\title{
Vegetable intake and the risk of bladder cancer in the BLadder Cancer Epidemiology and Nutritional Determinants (BLEND) international study
}

Evan Yi-Wen Yu ${ }^{1,2}$, Anke Wesselius ${ }^{1 *}$ (D), Siamak Mehrkanoon ${ }^{3}$, Mieke Goosens ${ }^{4}$, Maree Brinkman ${ }^{1,5,6}$, Piet van den Brandt ${ }^{7}$, Eric J. Grant ${ }^{8}$, Emily White ${ }^{9}$, Elisabete Weiderpass ${ }^{10}$, Florence Le Calvez-Kelm ${ }^{10}$, Marc J. Gunter ${ }^{10}$, Inge Huybrechts ${ }^{10}$, Elio Riboli ${ }^{11}$, Anne Tjonneland ${ }^{12,13}$, Giovanna Masala ${ }^{14}$, Graham G. Giles ${ }^{6,15,16}$, Roger L. Milne ${ }^{6,15,16}$ and Maurice P. Zeegers ${ }^{1,2,17}$

\begin{abstract}
Background: Although a potential inverse association between vegetable intake and bladder cancer risk has been reported, epidemiological evidence is inconsistent. This research aimed to elucidate the association between vegetable intake and bladder cancer risk by conducting a pooled analysis of data from prospective cohort studies.

Methods: Vegetable intake in relation to bladder cancer risk was examined by pooling individual-level data from 13 cohort studies, comprising 3203 cases among a total of 555,685 participants. Pooled multivariate hazard ratios (HRs), with corresponding $95 \%$ confidence intervals $(\mathrm{Cls})$, were estimated using Cox proportional hazards regression models stratified by cohort for intakes of total vegetable, vegetable subtypes (i.e. non-starchy, starchy, green leafy and cruciferous vegetables) and individual vegetable types. In addition, a diet diversity score was used to assess the association of the varied types of vegetable intake on bladder cancer risk.

Results: The association between vegetable intake and bladder cancer risk differed by sex ( -interaction $=0.011$ ) and smoking status ( $P$-interaction $=0.038)$; therefore, analyses were stratified by sex and smoking status. With adjustment of age, sex, smoking, energy intake, ethnicity and other potential dietary factors, we found that higher intake of total and non-starchy vegetables were inversely associated with the risk of bladder cancer among women (comparing the highest with lowest intake tertile: $\mathrm{HR}=0.79,95 \% \mathrm{Cl}=0.64-0.98, P=0.037$ for trend, $\mathrm{HR}$ per $1 \mathrm{SD}$ increment $=0.89,95 \% \mathrm{Cl}=0.81-0.99 ; \mathrm{HR}=0.78,95 \% \mathrm{Cl}=0.63-0.97, P=0.034$ for trend, $\mathrm{HR}$ per $1 \mathrm{SD}$ increment $=$ $0.88,95 \% \mathrm{Cl}=0.79-0.98$, respectively). However, no evidence of association was observed among men, and the intake of vegetable was not found to be associated with bladder cancer when stratified by smoking status. Moreover, we found no evidence of association for diet diversity with bladder cancer risk.

(Continued on next page)
\end{abstract}

\footnotetext{
* Correspondence: anke.wesselius@maastrichtuniversity.nl

'Department of Complex Genetics and Epidemiology, School of Nutrition and Translational Research in Metabolism, Maastricht University, Universiteitssingel 40 (Room C5.570), 6229 ER Maastricht, the Netherlands Full list of author information is available at the end of the article
}

C C The Author(s). 2021 Open Access This article is licensed under a Creative Commons Attribution 4.0 International License, which permits use, sharing, adaptation, distribution and reproduction in any medium or format, as long as you give appropriate credit to the original author(s) and the source, provide a link to the Creative Commons licence, and indicate if changes were made. The images or other third party material in this article are included in the article's Creative Commons licence, unless indicated otherwise in a credit line to the material. If material is not included in the article's Creative Commons licence and your intended use is not permitted by statutory regulation or exceeds the permitted use, you will need to obtain permission directly from the copyright holder. To view a copy of this licence, visit http://creativecommons.org/licenses/by/4.0/. The Creative Commons Public Domain Dedication waiver (http://creativecommons.org/publicdomain/zero/1.0/) applies to the data made available in this article, unless otherwise stated in a credit line to the data. 
(Continued from previous page)

Conclusion: Higher intakes of total and non-starchy vegetable are associated with reduced risk of bladder cancer for women. Further studies are needed to clarify whether these results reflect causal processes and potential underlying mechanisms.

Keywords: Bladder cancer, Vegetable, Dietary diversity analysis, Cohort study

\section{Background}

Bladder cancer is the most common malignancy of urinary tract, with an estimated 550,000 new cases and 200, 000 deaths annually [1-3]. Incidence rates of bladder cancer are highest in Europe and North America, with a strong predominance in men and the elderly [4-9]. Due to its high rate of recurrence, bladder cancer places costly burden on healthcare systems in terms of life time treatment [10]. Apart from well-established risk factors, such as smoking, occupational exposure and arsenic contamination [11-15], dietary factors may also contribute to bladder cancer development considering that many dietary compounds are excreted in urine and thereby come into direct contact with the bladder epithelium [12]. As recommended in numerous dietary guidelines globally, intake of vegetables may be beneficial for cancer prevention due to their rich content of vitamins, fibre, minerals, and other bioactive compounds [16-18]. However, the World Cancer Research Fund (WCRF) International's Continuous Update Project (CUP) 2018 [19] found that the evidence suggesting that higher intake of vegetable decreases the risk of bladder cancer is limited.

Previous epidemiologic studies on the influence of vegetable intake on bladder cancer risk have yielded inconsistent results. While most studies reported null association between total vegetable intake and bladder cancer risk, some showed conflicting results, with some showing inverse associations [20-24], and others that a higher intake increases the risk of bladder cancer [25]. A meta-analysis based on cohort studies only found no association between vegetable intake and bladder cancer risk [26], while those combining results from case-control and cohort studies showed an inverse association [27-29].

It remains unclear which vegetable subtype (e.g. nonstarchy, green leafy or cruciferous) or individual vegetable type (e.g. broccoli, garlic, cauliflower, kale, cabbage, asparagus) may be responsible for a possible inverse association with bladder cancer. The potential protective effect could, therefore, be the result of a cumulative influence of many preventative agents from total vegetable intake, or from a anticarcinogenic property of agents in a specific vegetable (i.e. isothiocyanates from broccoli [30-32], S-allylmercaptocysteine (SAMC) [33], and diallyl trisulfide (DATS) [34] from garlic).

This inconsistent evidence and lack of knowledge on which vegetable or which subtypes are possibly associated with bladder cancer risk could be due to the small sample sizes of previous studies and their consequent lack of statistical power to detect weak associations and perform subgroup analyses [27]. Therefore, this study aimed to obtain more conclusive results on the associations between intake of total vegetable and vegetable subtypes and bladder cancer risk by pooling data from 555,685 participants with 3203 bladder cancer cases in 13 cohort studies included in the BLadder Cancer Epidemiology and Nutritional Determinants (BLEND) international consortium.

\section{Methods \\ Study sample}

Data were obtained from BLEND, an international nutritional consortium currently consisting of 19 case-control studies and 16 cohort studies. Thirteen cohort studies with a total of 555,685 participants, 3203 of whom developed incident bladder cancer, had sufficient information on vegetable intake to be eligible for inclusion in the present study. These studies originated from 12 countries in 4 continents [i.e. Europe: European Prospective Investigation into Cancer and Nutrition cohort study (EPIC) [35] (Denmark [36], France [37], Germany [38], Italy [39], Spain [40], Sweden [41, 42], The Netherlands [43], UK [44, 45], Norway [46]), NetherLands Cohort Study (NLCS) [47]; North America: VITamins And Lifestyle cohort study (VITAL) [48]; Oceania: Melbourne Collaborative Cohort Study (MCCS) in Australia [49, 50]; and Asia: Radiation Effects Research FoundationLife Span Study (RERF-LSS) [51]]. Person-years of follow-up for each participant were calculated from the date of study enrolment until the date of bladder cancer diagnosis, or date of last follow-up (e.g. date of death, lost to follow-up, or study exit), whichever came first. For the NLCS study, a nested case-cohort design was applied in order to increase the follow-up coverage and efficiency, in which the number of person-years at risk was estimated based on a sub-cohort that was randomly sampled [47]. Each study was approved by their local ethical research committee [35, 47, 48, 50, 51] (Additional file 1: Table S1).

\section{Data collection and coding}

Details on the methodology of the BLEND consortium have been described elsewhere [52]. In brief, all included 
studies used self-administered or trained interviewer administered food frequency questionnaire (FFQ) that was validated on either food groups [48, 53-56], and/or energy intake $[53,56,57]$. For each study, participants were asked to report on their usual vegetable intake during the year before study enrolment. This data was harmonised and categorised in individual vegetable subtype intake using the hierarchal Eurocode 2 food coding system developed by the European Union [58], with weekly, monthly or yearly intake converted to grams (g) per day. The classification of the Eurocode 2 Food Coding System defines which food items are covered for what food category so that the potential for misidentification of foods will be limited.

Each study ascertained incident bladder cancer, defined to include all urinary bladder neoplasms according to the International Classification of Diseases for Oncology (ICD-O-3 code C67) using population-based cancer registries, health insurance records, or medical records. Bladder cancer was classified as non-muscle invasive bladder cancer (NMIBC) or muscle invasive bladder cancer (MIBC). NMIBC included non-invasive papillary carcinomas confined to the urothelium (stage Ta), carcinomas that invaded the lamina propria of the bladder wall (stage T1) and high grade flat non-invasive carcinomas confined to the urothelium (carcinoma in situ; CIS). MIBC included carcinomas that invaded into the detrusor muscle (stage T2), carcinomas that invaded into the peri-vesical tissue (stage T3) and carcinomas that invaded adjacent tissues and organs (most often the prostate or uterus, stage T4).

In addition to information on vegetable and other dietary intakes, the BLEND dataset also included data on study characteristics (design, method of dietary assessment, geographical region), participant demographics (age, sex and ethnicity), smoking status and smoking pack-years (i.e. the number of cigarettes smoked per day multiplying the years of smoking), which were measured at baseline.

\section{Statistical analyses}

To assess the influence of vegetable intake on bladder cancer risk, Cox regression analyses with a stratification approach to adjust for cross-cohort heterogeneity [59] were used to estimate the pooled hazard ratios (HRs) and 95\% confidence intervals (CIs). The proportional hazard assumption was examined for each analysis and no evidence of violation was found. Additionally, the appropriateness of the use of the log-normal distribution was tested using a Wald test, and again, no evidence of violation was found. The intake of total vegetable and the main vegetable subgroups [i.e. non-starchy (including 3162 cases/545,951), starchy (including 1514 cases/96, 108 participants), green leafy (including 3162 cases/574,
381 participants) and cruciferous (including 3162/574, 381 participants) (Additional file 1: Table S2)] were expressed as tertiles: low intake (tertile 1), medium intake (tertile 2) and high intake (tertile 3). Low intake was used as the reference group and associations were assessed applying two models. Model 1 was adjusted for age (years), sex (men and women), smoking and total energy intake [kilocalorie (kcal)/day, continuous]. Model 2 was additionally adjusted for ethnicity (Caucasian or non-Caucasian), alcohol intake [millilitre $(\mathrm{ml}) /$ day, continuous], sugar intake [gram (g)/day, continuous], meat intake (g/day, continuous), grain intake (g/day, continuous) and fat intake (g/day, continuous), which have been shown to be potential dietary risk factors for bladder cancer risk [60]. Smoking was defined as a dummy variable: 0 (never smokers); 1 [current light smokers (i.e. smoking less than 20 pack-years)]; 2 [current heavy smokers (i.e. smoking more than 20 pack-years)]; 3 [current smokers (no information on pack-years)]; 4 [former light smokers (i.e. smokers who ceased smoking over 1 year prior and smoked less than 20 pack-years)]; 5 [former heavy smokers (i.e. smokers who ceased smoking over 1 year prior and smoked more than 20 packyears)]; and 6 [former smokers (smokers who ceased smoking over 1 year prior and no information on packyears)]. Total energy intake was included in the models in addition to the energy adjustment of the residual model [61]. To understand the relevance of effect modification, the main interaction terms between tertiles of vegetable intake and age, sex and smoking status were added to model 1. P-interaction $<0.05$ was considered statistically significant where upon all analyses were stratified for the covariate of interest. A supplementary analysis was performed to examine the association of individual vegetables with bladder cancer risk based on the eligible cohorts with sufficient data.

In addition, the HRs and 95\% CIs of bladder cancer per 1 standard deviation (SD) increase in total vegetable and vegetable subgroups intake were estimated using the same models. To test for linearity or nonlinearity, we included both linear and quadratic terms (i.e. the absolute intake and intake squared) in the models and then used a likelihood ratio test to assess the difference between the nonlinear and linear models [62]. Since results showed no evidence of a non-linear association, linear models were applied. P for trend test was conducted by assigning medians to per $1 \mathrm{SD}$ increase in intake as a continuous variable in the models.

The variables of bladder cancer status (i.e. cases or non-cases), follow-up time, age, sex, smoking and total energy intake were complete without missing values. Missing values of variables (e.g. categorical: ethnicity; continuous: alcohol intake, sugar intake, meat intake, vegetable intake, and fat intake; missing proportion were 
all less than 5\%) were imputed by multiple imputation method. Since study protocols and characteristics of participants across cohorts might differ, multiple imputation was done separately for each included cohort study. Only participants with complete information on bladder cancer status, age, sex, smoking and total energy intake were included in building of the imputation models. Linear regression models were then fitted for those variables with missing data separately.

Besides assessing of the vegetable quantity, also the variety of vegetables intake was assessed. For this, a diet diversity score (DDS) was used to quantify the variety of vegetable intake $[52,53]$ and to assess the association of the varied types of vegetable intake on bladder cancer risk. DDS was calculated as the total number of different vegetable types reported according to the Eurocode 2 food coding system (i.e. leafy vegetables, Brassicas, stalk vegetables, shoot vegetables, onion-family vegetables, tubers, root vegetables, fruit vegetables, pod and seed vegetables, edible fungi and seaweeds) consumed at least once per week, without taking into account a minimum intake, and was then divided in 4 groups: $0-2$ low diversity, 2-4 median diversity, 4-6 high diversity and 6-8 very high diversity. To analyse the effect of variety in vegetable intake independent from the amount of vegetable intake, we adjusted the total vegetable intake for the DDS assessment.

A sensitivity analysis was performed by removing cases diagnosed within the first 2 years after recruitment to each study. Stratified analyses were performed for total and non-starchy vegetables by both sex and smoking status. In addition, the association between intake of total vegetable and risk of bladder cancer was assessed in each participating cohort separately and combined in a metaanalysis approach using a random-effect model. Finally, multiple testing for individual vegetable intake was performed by using false discovery rate (FDR) method.

All statistical analyses were performed using STATA version 14 SE (Stata Corporation, TX, USA) and R 4.0.2.. A two-tailed $P$ values $<0.05$ was considered statistically significant.

\section{Results}

Baseline characteristics of the included study samples are presented in Table 1 . In total, 555,685 study participants contributed 6,276,560 person-years of follow-up over a median of 11 years, with 3203 incident bladder cancer cases (2405 men, 798 women) diagnosed. Of these, $2040(64 \%)$ cases had available diagnosis records of NMIBC (40\%) or MIBC (24\%). The median age at baseline was 60 years for cases and 53 years for noncases. The majority (98.2\%) of participants were Caucasian. Higher intake of total vegetable, non-starchy vegetables, green leafy vegetable and cruciferous vegetable were observed in bladder cancer cases ( $P$ value $<0.001,<0.001,0.476$ and $<0.001$ respectively), while only higher intake of starchy vegetables was observed in non-bladder-cancer cases $(P$ value $<0.001)$.

\section{Associations of vegetable intake with bladder cancer risk Total vegetable intake and bladder cancer risk}

For the total vegetable intake, no evidence of association was observed for the overall population and neither for the bladder cancer subtypes (overall: $\mathrm{HR}_{\text {model2; }}$ highest vs lowest tertile $=0.95,95 \% \mathrm{CI}=0.85-1.07, P=0.285$ for trend, $\mathrm{HR}$ per $1 \mathrm{SD}$ increment $=0.96,95 \% \mathrm{CI}=0.91-1.01$; NMIBC: $\mathrm{HR}_{\text {model2; }}$ highest vs lowest tertile $=1.01,95 \% \mathrm{CI}=$ $0.84-1.21, P=0.404$ for trend, HR per $1 \mathrm{SD}$ increment $=$ 0.97, 95\% CI $=0.89-1.05$; MIBC: $\mathrm{HR}_{\text {model2; highest vs lowest }}$ tertile $=0.99,95 \% \mathrm{CI}=0.77-1.27, P=0.582$ for trend, $\mathrm{HR}$ per $1 \mathrm{SD}$ increment $=0.97,95 \% \mathrm{CI}=0.97-1.07)($ Table 2$)$. Sex-stratified analysis showed an inverse association between bladder cancer risk and high total vegetable intake among women $\left(\mathrm{HR}_{\text {model2; }}\right.$ highest vs lowest tertile $=0.79,95 \%$ $\mathrm{CI}=0.64-0.98, P=0.037$ for trend; HR per $1 \mathrm{SD}$ increment $=0.89,95 \% \mathrm{CI}=0.81-0.99$ ), while no association was observed among men $\left(\mathrm{HR}_{\text {model2; }}\right.$ highest vs lowest tertile $=1.01,95 \% \mathrm{CI}=0.88-1.14, P=0.905$ for trend; $\mathrm{HR}$ per $1 \mathrm{SD}$ increment $=0.99,95 \% \mathrm{CI}=0.94-1.03)$. Stratification for smoking only showed a marginally non-significant decreased bladder cancer risk per 1 SD increment of total vegetable intake among current smokers $\left(\mathrm{HR}_{\text {model2; }}\right.$ highest vs lowest tertile $=0.95,95 \% \mathrm{CI}=0.79-1.14, P=0.051$ for trend; $\mathrm{HR}$ per $1 \mathrm{SD}$ increment $=0.90,95 \% \mathrm{CI}=0.84-$ 1.00). No such decline in risk could be observed among never or former smokers (respectively, $\mathrm{HR}_{\text {model2; highest vs }}$ lowest tertile $=1.05,95 \% \mathrm{CI}=0.82-1.34, P=0.787$ for trend; HR per $1 \mathrm{SD}$ increment $=1.00,95 \% \mathrm{CI}=0.90-1.09$ ), and former smokers $\left(\mathrm{HR}_{\text {model2; }}\right.$ highest vs lowest tertile $=0.91,95 \%$ $\mathrm{CI}=0.77-1.09, P=0.675$ for trend; HR per $1 \mathrm{SD}$ increment $=0.99,95 \% \mathrm{CI}=0.94-1.09$ ).

\section{Subgroups of vegetable intake and bladder cancer risk}

No evidence of association was found between the intake of non-starchy ( $\mathrm{HR}_{\text {model2; }}$ highest vs lowest tertile $=0.95,95 \%$ $\mathrm{CI}=0.84-1.06, P=0.356$ for trend, HR per $1 \mathrm{SD}$ increment $=0.98,95 \% \mathrm{CI}=0.91-1.04)$, starchy $\left(\mathrm{HR}_{\text {model } 2 \text {; highest }}\right.$ vs lowest tertile $=0.95,95 \% \mathrm{CI}=0.82-1.09, P=0.209$ for trend, $\mathrm{HR}$ per $1 \mathrm{SD}$ increment $=0.96,95 \% \mathrm{CI}=0.89$ 1.02), green leafy $\left(H R_{\text {model2; }}\right.$, highest vs lowest tertile $=0.95,95 \%$ $\mathrm{CI}=0.84-1.07, P=0.856$ for trend, HR per $1 \mathrm{SD}$ increment $=0.99,95 \% \mathrm{CI}=0.96-1.03$ ) or cruciferous vegetables $\left(\mathrm{HR}_{\text {model2; }}\right.$ highest vs lowest tertile $=0.92,95 \% \mathrm{CI}=0.81-1.03$, $P=0.612$ for trend, HR per 1 SD increment $=0.98,95 \%$ $\mathrm{CI}=0.93-1.00$ ), and the risk of the bladder cancer in the overall population (Tables 3 and 4). Both bladder cancer subtype and smoking status stratified analyses showed similar results that no association for any of the vegetable 
Table 1 Characteristics of the study population (3203 cases and 552,482 non-cases) and vegetable intake

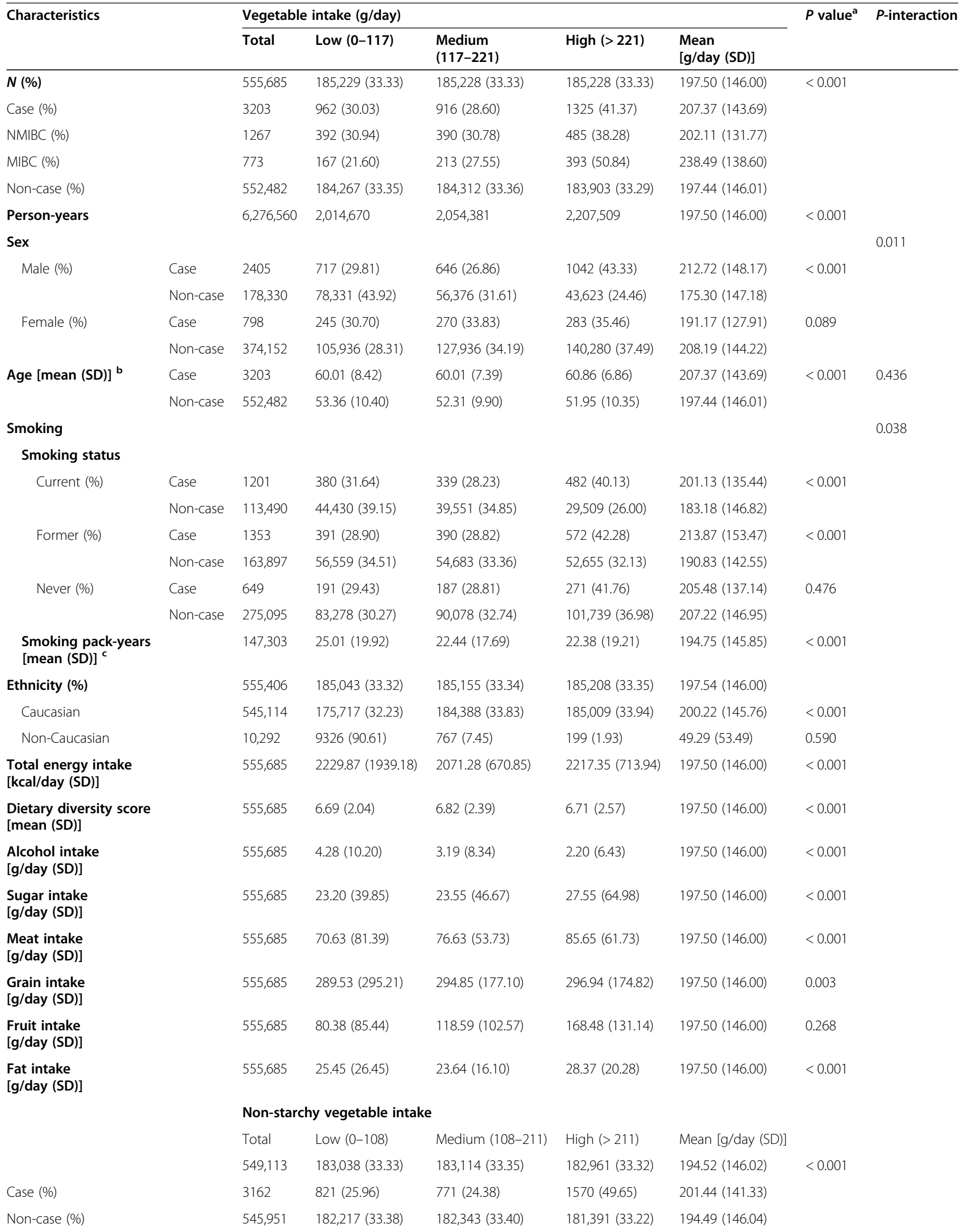


Table 1 Characteristics of the study population (3203 cases and 552,482 non-cases) and vegetable intake (Continued)

\begin{tabular}{|c|c|c|c|c|c|c|c|}
\hline \multirow[t]{2}{*}{ Characteristics } & \multicolumn{5}{|c|}{ Vegetable intake (g/day) } & \multirow[t]{2}{*}{$P$ value $^{\mathrm{a}}$} & \multirow[t]{2}{*}{$P$-interaction } \\
\hline & Total & Low (0-117) & $\begin{array}{l}\text { Medium } \\
(117-221)\end{array}$ & High (> 221) & $\begin{array}{l}\text { Mean } \\
\text { [g/day (SD)] }\end{array}$ & & \\
\hline & \multicolumn{5}{|c|}{ Starchy vegetable intake } & & \\
\hline & Total & Low $(0-7)$ & Medium (7-18) & High (> 18) & Mean [g/day (SD)] & & \\
\hline & 97,622 & $32,698(33.33)$ & $32,698(33.49)$ & $32,383(33.17)$ & $17.69(20.15)$ & $<0.001$ & \\
\hline Case (\%) & 1514 & $692(45.71)$ & $491(32.43)$ & $331(21.86)$ & $12.74(12.74)$ & & \\
\hline \multirow[t]{4}{*}{ Non-case (\%) } & 96,108 & $31,849(33.14)$ & $32,207(33.51)$ & $32,052(33.35)$ & $17.77(20.20)$ & & \\
\hline & \multicolumn{5}{|c|}{ Green leafy vegetable intake } & & \\
\hline & Total & Low (0-5) & Medium (5-23) & High (> 23) & Mean [g/day (SD)] & & \\
\hline & 549,113 & $183,039(33.33)$ & $183,037(33.33)$ & $183,037(33.33)$ & $23.85(35.29)$ & 0.476 & \\
\hline Case $(\%)$ & 3162 & $871(27.55)$ & $1045(33.05)$ & $1246(39.41)$ & $24.26(36.29)$ & & \\
\hline \multirow[t]{4}{*}{ Non-case (\%) } & 545,951 & $182,168(33.37)$ & $181,992(33.33)$ & $181,791(33.30)$ & $23.85(35.28)$ & & \\
\hline & \multicolumn{5}{|c|}{ Cruciferous vegetable intake } & & \\
\hline & Total & Low (0-7) & Medium (7-18) & High (> 18) & Mean [g/day (SD)] & & \\
\hline & 549,113 & $183,045(33.33)$ & $183,031(33.33)$ & $183,037(33.33)$ & $26.69(36.28)$ & $<0.001$ & \\
\hline Case (\%) & 3162 & 939 (29.70) & 1071 (33.87) & $1152(36.43)$ & $33.95(42.46)$ & & \\
\hline Non-case (\%) & 545,951 & $182,106(33.36)$ & $181,960(33.33)$ & 181,885 (33.32) & $26.65(36.24)$ & & \\
\hline
\end{tabular}

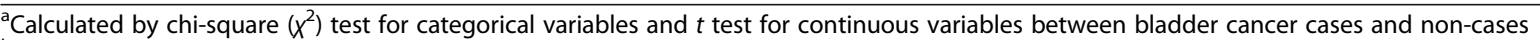

${ }^{\mathrm{b}}$ Age at the time of recruitment

'Pack-years was defined as the number of cigarettes smoked per day multiplying the years of smoking

Abbreviations: $S D$, standard deviation; $T N M$, tumour, nodes and metastasis classification; $g$, gram; $\mathrm{ml}$, millilitre; $k c a l$, kilocalorie; $M I B C$, muscle invasive

bladder cancer; $N M I B C$, non-muscle invasive bladder cancer; $D D S$, dietary diversity score

$P$ value $<0.05$ was considered statistically significant

$P$-interaction $<0.05$ was considered statistically significant

subtype intake and bladder cancer risk could be observed. Among women, however, an inverse association with bladder cancer risk was observed for the intake of nonstarchy vegetables $\left(\mathrm{HR}_{\text {model2; }}\right.$ highest vs lowest tertile $=0.78$, $95 \% \mathrm{CI}=0.63-0.97, P=0.034$ for trend; HR per $1 \mathrm{SD}$ increment $=0.88,95 \% \mathrm{CI}=0.79-0.98)$. No other vegetable subtype intake showed a significant association with bladder cancer risk neither in women nor in men.

\section{Individual vegetable type intake and bladder cancer risk}

A significant decreased bladder cancer risk was observed for high intake of curly kale $\left(\mathrm{HR}_{\text {model2; }}\right.$ highest vs lowest tertile $=0.80,95 \% \mathrm{CI}=0.68-0.95 ; \mathrm{HR}_{\text {model } 2 ; \text { medium vs lowest }}$ tertile $=0.86,95 \% \mathrm{CI}=0.73-1.00, P=0.072$ for trend; $\mathrm{HR}$ per $1 \mathrm{SD}$ increment $=0.94,95 \% \mathrm{CI}=0.87-1.01$ ). However, this association disappeared after correction for multiple testing. No other individual vegetable type showed a significant association with bladder cancer risk (Additional file 1: Table S3).

\section{Vegetable diversity intake and bladder cancer risk}

The HRs and 95\% CIs for different levels for the DDS and bladder cancer risk are presented in Table 5. There was no evidence of significant associations for DDS with bladder cancer risk (consuming 6-8 individual types versus $0-2$ individual types: $\mathrm{HR}_{\text {model } 2}=0.95,95 \% \mathrm{CI}=0.62-$ $1.44, P=0.340$ for trend).

\section{Sensitivity analysis}

Similar results for the intake of total vegetable with subgroups and bladder cancer risk was obtained from the sensitivity analysis when excluding bladder cancers diagnosed within the first 2 years after study entry (Additional file 1: Table S4). Stratified analyses by both sex and smoking status showed a similar inverse association between total and non-starchy vegetables and bladder cancer among never-smoking women $\left(\mathrm{HR}_{\text {model2; }}\right.$ highest vs lowest tertile $=0.59,95 \% \mathrm{CI}=0.39-0.90, \quad P$-trend $=0.013$; $\mathrm{HR}_{\text {model2; highest vs lowest tertile }}=0.65,95 \% \mathrm{CI}=0.40-0.97$, $P$-trend $=0.079$, respectively) (Additional file 1 : Table S5). In addition, the meta-analysis presented similar inverse association between total vegetable intake and bladder cancer for women $\left(\mathrm{HR}_{\text {model2; }}\right.$ highest vs lowest tertile $=0.66,95 \% \mathrm{CI}=0.49-0.83$ ), while no association for overall population and men; in addition, only the EPIC study showed a reduced risk of bladder cancer in overall population $\left(\mathrm{HR}_{\text {model2; }}\right.$ highest vs lowest tertile $=0.69,95 \% \mathrm{CI}=$ $0.61-0.79)$ and women $\left(\mathrm{HR}_{\text {model2; }}\right.$ highest vs lowest tertile $=$ 0.56, 95\% CI $=0.45-0.71$ ) (Additional file 1: Table S6 and Fig. S1).

\section{Discussion}

In this large multi-centre prospective cohort study, we found an inverse association between intake of total and non-starchy vegetables and bladder cancer risk among 
Table 2 Adjusted hazard ratios and 95\% confidence intervals of bladder cancer according to intake of vegetable stratified by subtype, sex and smoking status

\begin{tabular}{|c|c|c|c|c|c|c|}
\hline \multirow{2}{*}{$\begin{array}{l}\text { Study } \\
\text { subgroup }\end{array}$} & \multirow{2}{*}{$\begin{array}{l}\text { Model } \\
\text { adjustments }\end{array}$} & \multicolumn{3}{|c|}{ Vegetable intake (g/day) } & \multirow{2}{*}{$\begin{array}{l}\text { HR per } 1 \text { SD } \\
\text { increase } \\
(95 \% \mathrm{Cl})\end{array}$} & \multirow{2}{*}{$\begin{array}{l}P \text { - } \\
\text { trend }\end{array}$} \\
\hline & & Low (0-117) & Medium (117-221) & High (> 221) & & \\
\hline \multirow[t]{3}{*}{ Overall } & No. Cases & 962 & 916 & 1325 & & \\
\hline & Model $1^{d}$ & Ref. & $1.02(0.91-1.13)$ & $0.96(0.86-1.07)$ & $0.97(0.91-1.02)$ & 0.417 \\
\hline & Model $2^{\text {d, e }}$ & Ref. & $1.01(0.90-1.11)$ & $0.95(0.85-1.07)$ & $0.96(0.91-1.01)$ & 0.285 \\
\hline \multirow[t]{3}{*}{ NMIBC } & No. Cases & 392 & 390 & 485 & & \\
\hline & Model $1^{d}$ & Ref. & $1.10(0.94-1.28)$ & $1.02(0.85-1.22)$ & $0.98(0.90-1.06)$ & 0.586 \\
\hline & Model $2^{\text {d, e }}$ & Ref. & $1.10(0.94-1.28)$ & $1.01(0.84-1.21)$ & $0.97(0.89-1.05)$ & 0.404 \\
\hline \multirow[t]{3}{*}{ MIBC } & No. Cases & 167 & 213 & 393 & & \\
\hline & Model $1^{d}$ & Ref. & $1.12(0.89-1.41)$ & $1.00(0.78-1.28)$ & $0.98(0.89-1.08)$ & 0.682 \\
\hline & Model $2^{\text {d, e }}$ & Ref. & $1.12(0.89-1.41)$ & $0.99(0.77-1.27)$ & $0.97(0.88-1.07)$ & 0.582 \\
\hline \multirow[t]{3}{*}{ Male } & No. Cases & 717 & 646 & 1042 & & \\
\hline & Model $1^{\mathrm{d}}$ & Ref. & $1.03(0.91-1.15)$ & $1.02(0.89-1.16)$ & $1.00(0.95-1.04)$ & 0.826 \\
\hline & Model $2^{d, e}$ & Ref. & $1.02(0.89-1.14)$ & $1.01(0.88-1.14)$ & $0.99(0.94-1.03)$ & 0.905 \\
\hline \multirow[t]{3}{*}{ Female } & No. Cases & 245 & 270 & 283 & & \\
\hline & Model $1^{d}$ & Ref. & $0.89(0.74-1.06)$ & $0.79(0.64-0.98)$ & $0.89(0.81-0.99)$ & 0.034 \\
\hline & Model $2^{d, e}$ & Ref. & $0.89(0.74-1.07)$ & $0.79(0.64-0.98)$ & $0.89(0.81-0.99)$ & 0.037 \\
\hline \multirow[t]{3}{*}{ Never smoker } & No. Cases & 191 & 187 & 271 & & \\
\hline & Model $1^{d}$ & Ref. & $1.04(0.85-1.28)$ & $1.06(0.84-1.35)$ & $1.01(0.91-1.10)$ & 0.712 \\
\hline & Model $2^{\text {d, e }}$ & Ref. & $1.03(0.83-1.26)$ & $1.05(0.82-1.34)$ & $1.00(0.90-1.09)$ & 0.787 \\
\hline \multirow[t]{3}{*}{ Current smoker } & No. Cases & 380 & 339 & 482 & & \\
\hline & Model $1^{\mathrm{d}}$ & Ref. & $1.00(0.87-1.14)$ & $0.96(0.80-1.15)$ & $0.91(0.83-1.01)$ & 0.073 \\
\hline & Model $2^{\text {d, e }}$ & Ref. & $0.99(0.85-1.16)$ & $0.95(0.79-1.14)$ & $0.90(0.84-1.00)$ & 0.051 \\
\hline \multirow[t]{3}{*}{ Former smoker } & No. Cases & 410 & 402 & 554 & & \\
\hline & Model $1^{\mathrm{d}}$ & Ref. & $1.00(0.86-1.16)$ & $0.92(0.78-1.10)$ & $0.98(0.95-1.07)$ & 0.610 \\
\hline & Model $2^{\text {d, e }}$ & Ref. & $0.99(0.85-1.15)$ & $0.91(0.77-1.09)$ & $0.99(0.94-1.09)$ & 0.675 \\
\hline
\end{tabular}

dModel 1: Adjusted for age (years, continuous), sex (male or female, if applicable), smoking (if applicable, smoking was defined as 0 (never smokers); 1 [current light smokers (i.e. smoking less than 20 pack-years)]; 2 [current heavy smokers (i.e. smoking more than 20 pack-years)]; 3 [current smokers (no information on pack-years)]; 4 [former light smokers (i.e. smokers who ceased smoking over 1 year prior and smoked less than 20 pack-years)]; 5 [former heavy smokers (i.e. smokers who ceased smoking over 1 year prior and smoked more than 20 pack-years)]; 6 [former smokers (smokers who ceased smoking over 1 year prior and no information on pack-years)]) and total energy intake (kcal/day, continuous)

d, e Model 2: Additionally, ethnicity (Caucasian or non-Caucasian, if applicable), alcohol intake (ml/day, continuous), fat intake (g/day, continuous), meat intake (g/ day, continuous), sugar intake (g/day, continuous) and grain intake ( $\mathrm{g} / \mathrm{day}$, continuous)

Abbreviations: NMIBC, non-muscle invasive bladder cancer; MIBC, muscle invasive bladder cancer; SD, standard deviation; $k c a l$, kilocalorie; $g$, gram

Reference group was lowest intake (tertile 1 )

$P$-trend $<0.05$ was considered statistically significant

women. This association, however, was not observed among men or for the overall population.

The observed null associations in the overall population and in men are in line with two previously conducted meta-analyses, including cohort studies only [26, 29 ], also showing no or little evidence of an inverse association of higher vegetable intake on bladder cancer risk. However, two other meta-analyses, including both casecontrol studies and cohort studies, showed an inverse association of vegetable intake and bladder cancer risk [27, 28]. A possible explanation for this observed discrepancy in results might be the inclusion of different study designs. Results obtained from long-term cohort studies, who prospectively obtained data, are suggested of substantially superior quality to those obtained from casecontrol studies. Another explanation could be that "total vegetable intake" may vary in its constituents (i.e. different individual vegetable types included) across different studies. However, our DDS analyses showed no association between the vegetable diversity and bladder cancer risk.

In the present study, a reduced risk of bladder cancer was found among women consuming high levels of "total vegetable" and non-starchy vegetables. Similar results were shown by other large prospective cohort studies, including EPIC, which also showed an inverse 


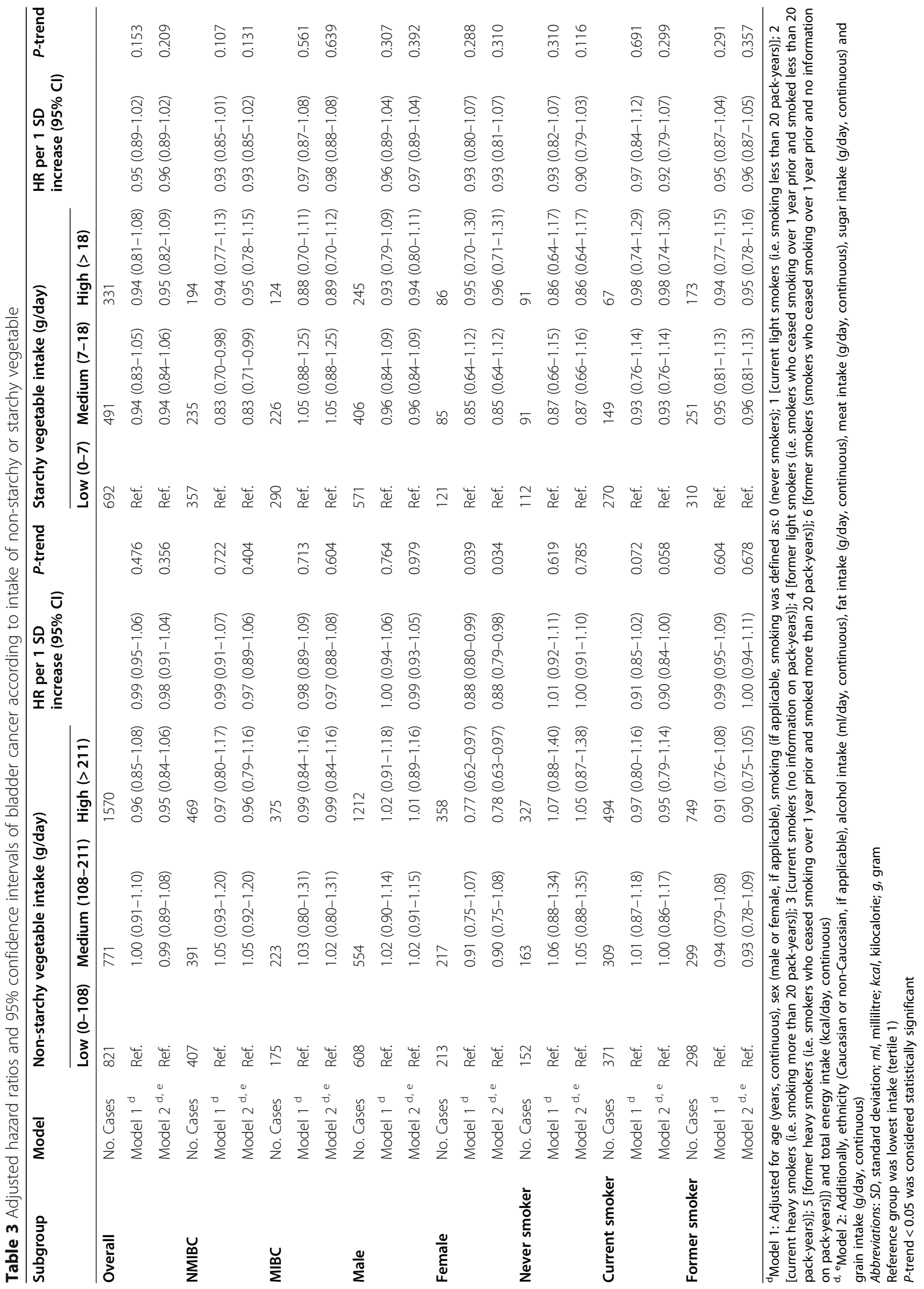




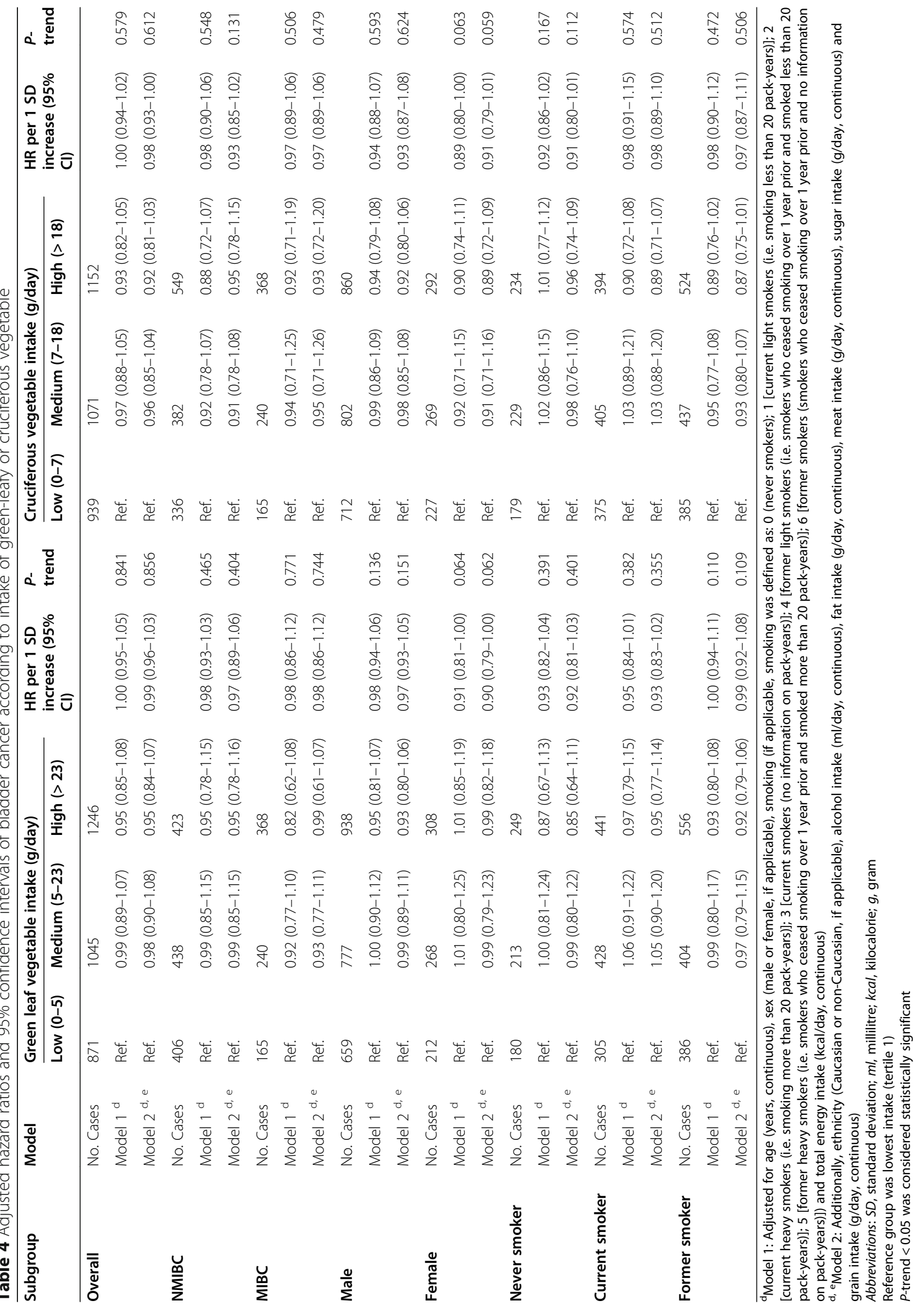


Table 5 Adjusted hazard ratios and 95\% confidence intervals of bladder cancer according to diet diversity scores

\begin{tabular}{|c|c|c|c|c|c|}
\hline \multirow{2}{*}{$\begin{array}{l}\text { Model } \\
\text { adjustments }\end{array}$} & \multicolumn{4}{|c|}{ Diet diversity scores of vegetable } & \multirow{2}{*}{$\begin{array}{l}P \text { - } \\
\text { trend }\end{array}$} \\
\hline & $0-2$ & $2-4$ & $4-6$ & $6-8$ & \\
\hline No. Cases & 27 & 962 & 1937 & 277 & \\
\hline Model $1^{\mathrm{f}}$ & Ref. & $0.88(0.60-1.32)$ & $0.92(0.61-1.38)$ & $0.95(0.62-1.45)$ & 0.382 \\
\hline Model $2^{f, g}$ & Ref. & $0.87(0.61-1.30)$ & $0.92(0.60-1.37)$ & $0.95(0.62-1.44)$ & 0.340 \\
\hline
\end{tabular}

fModel 1: Adjusted for age (years, continuous), sex (male or female, if applicable), smoking (if applicable, smoking was defined as: 0 (never smokers); 1 [current light smokers (i.e. smoking less than 20 pack-years)]; 2 [current heavy smokers (i.e. smoking more than 20 pack-years)]; 3 [current smokers (no information on pack-years)]; 4 [former light smokers (i.e. smokers who ceased smoking over 1 year prior and smoked less than 20 pack-years)]; 5 [former heavy smokers (i.e. smokers who ceased smoking over 1 year prior and smoked more than 20 pack-years)]; 6 [former smokers (smokers who ceased smoking over 1 year prior and no information on pack-years)]), total energy intake ( $\mathrm{kcal} /$ day, continuous) and total vegetable intake

f, g Model 2: Additionally, ethnicity (Caucasian or non-Caucasian, if applicable), alcohol intake (ml/day, continuous), fat intake (g/day, continuous), meat intake (g/ day, continuous), sugar intake (g/day, continuous) and grain intake (g/day, continuous)

Abbreviations: NMIBC, non-muscle invasive bladder cancer; MIBC, muscle invasive bladder cancer; $S D$, standard deviation; $k c a l$, kilocalorie; $g$, gram

Reference group was lowest intake (tertile 1)

$P$-trend $<0.05$ was considered statistically significant

association of total vegetable intake among women only $[22,63,64]$. In addition, results from a previous BLEND study investigating the influence of vegetable intake on bladder cancer in case-control studies showed an inverse association among women, while a borderline decreased risk of bladder cancer was observed among men.

Although the evidence on the exact mechanism is lacking, some potential mechanisms could attribute to the observed difference between men and women: (1) hormones (e.g. oestrogen)-experimental studies showed that nutrients or chemicals obtained from vegetable have the potential to modulate the effect of endogenous hormones and thereby inhibit the development of bladder cancer among women [65]; (2) gene mutation-the protective effect of vegetables against cancer was found to be presented on some gene mutations only related to women [e.g. epidermal growth factor receptor (EGFR)] [66]; (3) urination habits-while men empty their bladder mainly in a standing position, women crouch over the toilet to empty the bladder without relaxation of the pelvic floor. This might cause urine retention, which results in a longer contact time between the metabolites of vegetable and the bladder [67]; and (4) behavioural vegetable intake-evidence showed that the vegetable intake in women is more persistently compared to men, which may lead to the consequence that the long-term benefit of vegetables is more pronounced in women [68-70]. However, it could not be excluded that residual confounding by other factors might explain the sex difference. Future research is, therefore, needed to clarify this finding and provide better understanding of how vegetable influence bladder cancer risk in terms of sexes.

The WCRF/AICR CUP reported suggestive but not conclusive protective effects of non-starchy vegetables on bladder cancer risk [71, 72]. In addition, by summarising 10 primary studies on non-starchy vegetable intake and bladder cancer risk, the WCRF/AICR CUP reported a borderline decreased bladder cancer risk per 1 serving/ day increment of non-starchy vegetable intake (RR (relative risk) $=0.97,95 \% \mathrm{CI}=0.94-1.00$ ). The present study supports these findings by showing that a higher intake of non-starchy vegetables decreases the risk of bladder cancer among women. However, the biological mechanism for the role of non-starchy vegetables in the process of bladder carcinogenesis remains unclear.

In contrast to the inverse association of non-starchy vegetables on bladder cancer, a null association was observed for starchy vegetables. This finding is in line with a previous case-control study, which also reported a null association between higher starchy vegetables intake and bladder cancer risk. Starchy vegetables can raise blood sugar levels faster than non-starchy vegetables, resulting in an increased glycaemic loading and insulin response, and may thereby resist the suggested inverse association between vegetables and bladder cancer [73].

Green leafy vegetables contain several antioxidant nutrients, minerals, dietary fibre, phenols, flavonoids and phytochemicals [74-76], which may reduce oxidative stress and DNA damage caused by free radicals, and affect pathways controlling cell proliferation and apoptosis [77]. However, surprisingly no inverse association of this vegetable subtype could be observed in the present study or in any previously conducted prospective cohort studies [78, 79]. Null association in epidemiological studies may be the result of a limited amount range of intake, and thereby insufficient power to detect an association.

Cruciferous vegetables, in particular broccoli, contain high levels of glucosinolates. During food preparation, glucosinolates are transformed into isothiocyanates, which are suggested to favourably modify the carcinogen metabolism via inhibition of phase 1 enzymes and/or induction of phase 2 enzymes [80]. Several pooled results from case-control studies indeed showed an inverse 
association of cruciferous vegetables intake and bladder cancer risk $[60,81]$.

In the present study, however, this hypothesis could not be strengthened, since results showed a null association between cruciferous vegetable intake and bladder cancer risk. A similar null-finding was observed by the WCRF/AICR International's CUP [19], who conducted a meta-analysis on results from 7 primary cohort studies, and by a meta-meta-analysis conducted by Al-Zalabani et al. [60] who pooled results from 2 meta-analyses of cohort studies. The discrepancy, between these epidemiological studies, might again be caused by the different study design of the included primary studies. Further studies with more optimal study design and dietary intake assessment methods (e.g. including more accurate assessments of individual vegetable types) need to be conducted in order clarify the associations between subtypes of vegetable and bladder cancer risk and the potential mechanisms.

The present study found a significant inverse association of high curly kale intake and bladder cancer risk. Although the exact mechanism of a protective effect of curly kale on carcinogenesis is lacking, it is reported to be one of the most nutrient-dense vegetables and might therefore help to prevent cancer [82]. It should be noted, however, that the observed association between curly kale and bladder cancer disappeared after correction for multiple testing. However, correction for multiple testing is likely too conservative when testing a priori hypotheses. Since we were able to formulate a plausible a priori hypothesis regarding the beneficial effect of curly kale [82], we believe that the observed protective effect is a true finding.

Null findings of other individual vegetable types might be caused by the fact that the intake of vegetable (sub) types individually does not reach a certain level which is needed to influence bladder cancer development. In addition, although BLEND provided enough statistical power for most individual vegetable subtypes, some subtypes (i.e. starchy vegetables) might have lacked sufficient power to detect small effect sizes. Future observational or experimental research aiming to investigate the effect of the intake of individual vegetable subtypes in preventing bladder cancer is warranted.

The effect of vegetables on bladder cancer risk may interact with smoking. Several experimental studies have reported a group of natural phytochemicals uniquely present in vegetables can modulate the smoking-related carcinogen metabolism and facilitate carcinogen detoxification, thus inhibiting smoking-related carcinogenesis [83-86]. This could potentially lead to a difference in the effect of vegetable intake on bladder cancer when stratifying for smoking status. Further research is needed to elucidate the potential interactive effect of smoking with vegetable intake on bladder cancer risk.
For the present study, data were pooled from 14 prospective cohorts, to obtain a sample size, large enough to permit detailed analyses with good precision. The study, however, also has some limitations: (a) other than age, sex and smoking, limited information was available on other possible risk factors, for the development of bladder cancer, such as body mass index (BMI), physical activity, socioeconomic status (SES), disinfection byproducts, arsenic in the drinking water and occupational exposures to potentially carcinogenic chemicals; (b) some tumour subtype (i.e. muscle-invasive/non-muscleinvasive) information was missing, which hampered the statistical power required for stratified subgroup analyses; (c) people with a high intake of vegetables might have generally healthier lifestyles and diets than those with a low intake; thus, we could not rule out the possibility that some of the associations could be more likely due to a healthy lifestyle than to vegetable intake per se; (d) sample size for starchy and individual vegetables was smaller, which may have caused insufficient statistical power for detailed analyses; (e) although we found similar results after adjusting for potential dietary risk factors, it is still possible that the observed associations were confounded by other dietary constituents or additives associated with vegetable intake; (f) for most cohorts, the exposure variable was assessed by FFQs. Therefore, measurement error and misclassification of study participants in terms of the exposure and outcome are unavoidable. Moreover, since the level of detail in FFQs was varied in different cohorts, some individual vegetables investigated in this study could not be covered across all cohorts; (g) another concern is that competing risk could have influenced our results, and that assuming a higher vegetable intake would result in a lower risk of premature death could have biased our association towards null. However, due to lack of information on loss-to-follow up of non-cases (as well as cases), we were unable to perform competing risk analysis; (h) the present study sample consists mostly of Caucasians, and this may limit the generalizability of our results to other racial/ethnic populations or geographic regions; (i) although status as well as duration and intensity of smoking were taken into account in our analysis, the adjustment for smoking might still be imperfect due to differences in smoking practices (e.g. depth of inhalation or amount of inhalation), differences in types of smoke exposure, or lack of information on passive smoking [87]; (j) there is limited mechanistic evidence to interpret our findings; therefore, further studies are needed to clarify whether there is an underlying mechanism for the association between intake of vegetable and bladder cancer risk, especially for women; (k) another concern that needs to be considered is whether the results were caused by chance alone. Within this study, it is possible 
that the findings are a consequence of multiple testing. However, although large numbers of statistical techniques are available to correct for multiple comparison, it still remains a topic of discussion whether and how to correctly adjust for multiple testing [58, 59]. Given the fact that most of the observed significant findings (i.e. total vegetable and non-starchy vegetable) are supported by a plausible biological evidence, it is unlike these results are chance findings.

\section{Conclusion}

In summary, the present study, including over 3200 cases of incident bladder cancer occurring in almost 0.6 million participants, indicates no overall relationship observed for the association of bladder cancer and intake of vegetables. Upon further sex-specific analyses, an association was observed among women. Future studies are needed to clarify the exact mechanism of this protective effect and should consider sex differences when investigating the association between vegetable intake and bladder cancer risk.

\section{Supplementary Information}

The online version contains supplementary material available at https://doi. org/10.1186/s12916-021-01931-8.

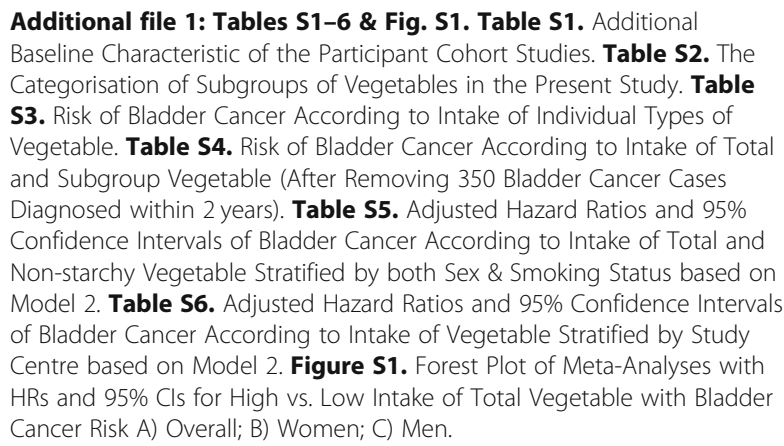

\section{Abbreviations \\ AIRC: American Institute for Cancer Research; BLEND: BLadder cancer Epidemiology and Nutritional Determinants; BMI: Body mass index; Cl: Confidence interval; CUP: Continuous Update Project; DATS: Diallyl trisulfide; DDS: Diet diversity score; EPIC: European Prospective Investigation into Cancer and Nutrition cohort study; FFQ: Food frequency questionnaire; HR: Hazard ratio; ICD-O: International Classification of Diseases for Oncology; MCCS: Melbourne Collaborative Cohort Study; MIBC: Muscle-invasive bladder cancer; NLCS: NetherLands Cohort Study; NMIBC: Non-muscle-invasive bladder cancer; RERF-LSS: Radiation, Effects Research Foundation-Life Span Study; SAMC: S-Allylmercaptocysteine; SD: Standard deviation; SES: Socioeconomic status; VITAL: VITamins And Lifestyle cohort study; WCRF: World Cancer Research Fund}

\section{Acknowledgements}

We gratefully acknowledge all principal investigators for their willingness to participate in this jointed project.

\section{Disclaimer}

Where authors are identified as personnel of the International Agency for Research on Cancer/World Health Organization, the authors alone are responsible for the views expressed in this article and they do not necessarily represent the decisions, policy or views of the International Agency for Research on Cancer/World Health Organization.

\section{Authors' contributions}

The authors' responsibilities were as follows-AW and MPZ: conceived and designed the study; EYWY: conducted data analyses and interpretation and drafted the manuscript; MB, PvdB, EW, EW, FLC-K, MJG, IH, ER, AT, GM, GGG and RLM: provided the data; MB, PvdB, EW, EW, FLC-K, MJG, IH, ER, AT, GM, GGG, RLM, AW, SM and MPZ: revised the manuscript; and all authors: read and approved the final manuscript.

\section{Funding}

This work was partly funded by the World Cancer Research Fund International (WCRF 2012/590) and European Commission (FP7-PEOPLE618308)

The Netherlands Cohort Study on diet and cancer was supported by the Dutch Cancer Society. The RERF atomic bomb survivors Study was supported by The Radiation Effects Research Foundation (RERF), Hiroshima and Nagasaki, Japan, a public interest foundation funded by the Japanese Ministry of Health, Labour and Welfare (MHLW) and the US Department of Energy (DOE). The research was also funded in part through DOE award DEHS0000031 to the National Academy of Sciences. This publication was supported by RERF Research Protocol RP-A5-12. The VITamins and Lifestyle Study (VITAL) was supported by a grant (R01CA74846) from the National Cancer Institute. The European Prospective Investigation into Cancer and Nutrition (EPIC) was carried out with financial support of the "Europe Against Cancer" Programme of the European Commission (SANCO); Lique contre le Cancer (France); Société 3 M (France); Mutuelle Générale de l'Éducation Nationale; Institut National de la Santé et de la Recherche Médicale (INSERM); Institute Gustave Roussy; German Cancer Aid; German Cancer Research Centre; German Federal Ministry of Education and Research; Danish Cancer Society; Health Research Fund (FIS) of the Spanish Ministry of Health; the Spanish Regional Governments of Andalucía, Asturias, Basque Country, Murcia and Navarra; Cancer Research UK; Medical Research Council, UK; Stroke Association, UK; British Heart Foundation; Department of Health, UK; Food Standards Agency, UK; Wellcome Trust, UK; Italian Association for Research on Cancer; Italian National Research Council; Dutch Ministry of Public Health, Welfare and Sports; Dutch Prevention Funds; LK Research Funds; Dutch ZON (Zorg Onderzoek Nederland); World Cancer Research Fund; Swedish Cancer Society; Swedish Scientific Council; Regional Government of Skane, Sweden; Norwegian Cancer Society; Norwegian Research Council. Partial support for the publication of this supplement was provided by the Centre de Recherche et d'Information Nutritionnelles (CERIN). Melbourne Collaborative Cohort Study (MCCS) cohort recruitment was funded by Cancer Council Victoria [http:// www.cancervic.org.au/] and VicHealth [https://www.vichealth.vic.gov.au/]. The MCCS was further augmented by Australian National Health and Medical Research Council grants 209057, 396414 and 1074383 and by infrastructure provided by Cancer Council Victoria. Cases and their vital status were ascertained through the Victorian Cancer Registry and the Australian Institute of Health and Welfare, including the National Death Index and the Australian Cancer Database.

\section{Availability of data and materials}

The data that support the findings of this study are available on reasonable request pending approval from the corresponding author, AW. The data are not publicly available owing to their containing information that could compromise the privacy of research participants.

\section{Ethics approval and consent to participate}

Each participating study has been approved by the local ethic committee. Informed consent was obtained from all individual participants included in each study.

Consent for publication

Not applicable.

Competing interests

The authors declare no competing interests. 


\section{Author details}

'Department of Complex Genetics and Epidemiology, School of Nutrition and Translational Research in Metabolism, Maastricht University, Universiteitssingel 40 (Room C5.570), 6229 ER Maastricht, the Netherlands. ${ }^{2}$ CAPHRI School for Public Health and Primary Care, Maastricht University, Maastricht, The Netherlands. ${ }^{3}$ Department of Data Science and Knowledge Engineering, Maastricht University, Maastricht, The Netherlands. ${ }^{4}$ Department of General Practice, Katholieke Universiteit Leuven, ACHG-KU Leuven, Leuven, Belgium. ${ }^{5}$ Department of Clinical Studies and Nutritional Epidemiology, Nutrition Biomed Research Institute, Melbourne, Australia. ${ }^{6}$ Cancer Epidemiology Division, Cancer Council Victoria, 615 St Kilda Road, Melbourne, Victoria 3004, Australia. ${ }^{7}$ Department of Epidemiology, Schools for Oncology and Developmental Biology and Public Health and Primary Care, Maastricht University Medical Centre, Maastricht, The Netherlands. ${ }^{8}$ Department of Epidemiology Radiation Effects Research Foundation, Hiroshima, Japan. ${ }^{9}$ Fred Hutchinson Cancer Research Center, Seattle, WA, USA. ${ }^{10}$ International Agency for Research on Cancer World Health Organization, Lyon, France. ${ }^{11}$ Department of Epidemiology and Biostatistics, School of Public Health, Imperial College London, London, UK. ${ }^{2}$ Danish Cancer Society Research Center, Copenhagen, Denmark. ${ }^{13}$ Department of Public Health, University of Copenhagen, Copenhagen, Denmark. ${ }^{14}$ Molecular and Lifestyle Epidemiology Branch, Cancer Risk Factors and Lifestyle Epidemiology Unit, Institute for Cancer Research, Prevention and Clinical Network ISPRO, Florence, Italy. ${ }^{15}$ Centre for Epidemiology and Biostatistics, Melbourne School of Population and Global Health, The University of Melbourne, 207 Bouverie Street, Melbourne, Victoria 3010, Australia. ${ }^{16}$ Precision Medicine, School of Clinical Sciences at Monash Health, Monash University, Clayton, Victoria 3168, Australia. ${ }^{17}$ School of Cancer Sciences, University of Birmingham, Birmingham, UK.

Received: 17 November 2020 Accepted: 29 January 2021

Published online: 09 March 2021

\section{References}

1. Siegel RL, Miller KD, Jemal A. Cancer statistics, 2019. CA Cancer J Clin. 2019; 69(1):7-34. https://doi.org/10.3322/caac.21551.

2. Richters $\mathrm{A}$, Aben $\mathrm{KKH}$, Kiemeney L. The global burden of urinary bladder cancer: an update. World J Urol. 2019. https://doi.org/10.1007/s00345-019-02 984-4.

3. Bray F, Ferlay J, Soerjomataram I, Siegel RL, Torre LA, Jemal A. Global cancer statistics 2018: GLOBOCAN estimates of incidence and mortality worldwide for 36 cancers in 185 countries. CA Cancer J Clin. 2018;68(6):394-424. https://doi.org/10.3322/caac.21492.

4. Antoni S, Ferlay J, Soerjomataram I, Znaor A, Jemal A, Bray F. Bladder cancer incidence and mortality: a global overview and recent trends. Eur Urol. 2017;71(1):96-108. https://doi.org/10.1016/j.eururo.2016.06.010.

5. Jemal A, Bray F, Center MM, Ferlay J, Ward E, Forman D. Global cancer statistics. CA Cancer J Clin. 2011;61(2):69-90. https://doi.org/10.3322/caa c.20107.

6. Ploeg M, Aben KK, Kiemeney LA. The present and future burden of urinary bladder cancer in the world. World J Urol. 2009;27(3):289-93. https://doi. org/10.1007/s00345-009-0383-3.

7. Marugame T, Mizuno S. Comparison of prostate cancer mortality in five countries: France, Italy, Japan, UK and USA from the WHO mortality database (1960-2000). Jpn J Clin Oncol. 2005;35(11):690-1. https://doi.org/1 0.1093/jjco/hyi185

8. Stewart B, Wild CP. World cancer report 2014. International Agency for Research on Cancer, World Health Organization. Geneva: WHO Press; 2017.

9. Letašiová S, Medved’ová A, Šovčíková A, et al. Bladder cancer, a review of the environmental risk factors. Environ Health. 2012;11(Suppl 1):S11. https:// doi.org/10.1186/1476-069X-11-S1-S11.

10. Botteman MF, Pashos CL, Redaelli A, Laskin B, Hauser R. The health economics of bladder cancer. Pharmacoeconomics. 2003;21(18):1315-30. https://doi.org/10.1007/BF03262330.

11. Al-Zalabani AH, Stewart KF, Wesselius A, Schols AM, Zeegers MP. Modifiable risk factors for the prevention of bladder cancer: a systematic review of meta-analyses. Eur J Epdemiol. 2016;31(9):811-51. https://doi.org/10.1007/s1 0654-016-0138-6.

12. Piyathilake C. Dietary factors associated with bladder cancer. Invest Clin Urol. 2016;57(Suppl 1):S14-25. https://doi.org/10.4111/icu.2016.57.S1.S14.
13. Johansson SL, Cohen SM. Epidemiology and etiology of bladder cancer. Semin Surg Oncol. 1997;13(5):291-8. https://doi.org/10.1002/(sici)1098-23 88(199709/10)13:5<291::aid-ssu2>3.0.co;2-8.

14. Thun M, Linet MS, Cerhan JR, Haiman CA, Schottenfeld D. Cancer epidemiology and prevention. New York: Oxford University Press; 2017.

15. Oberoi S, Barchowsky A, Wu F. The global burden of disease for skin, lung, and bladder cancer caused by arsenic in food. Cancer Epidemiol Biomark Prevent. 2014;23(7):1187-94. https://doi.org/10.1158/1055-9965.Epi-13-1317.

16. Kushi LH, Doyle C, McCullough M, Rock CL, Demark-Wahnefried W, Bandera EV, et al. American Cancer Society guidelines on nutrition and physical activity for cancer prevention: reducing the risk of cancer with healthy food choices and physical activity. CA Cancer J Clin. 2012;62(1):30-67. https://doi. org/10.3322/caac.20140.

17. Bradbury KE, Appleby PN, Key TJ. Fruit, vegetable, and fiber intake in relation to cancer risk: findings from the European Prospective Investigation into Cancer and Nutrition (EPIC). Am J Clin Nutr. 2014;100(Suppl 1):394s-8s. https://doi.org/10.3945/ajcn.113.071357.

18. Aune D, Giovannucci E, Boffetta P, Fadnes LT, Keum N, Norat T, et al. Fruit and vegetable intake and the risk of cardiovascular disease, total cancer and all-cause mortality-a systematic review and dose-response meta-analysis of prospective studies. Int J Epidemiol. 2017;46(3):1029-56. https://doi.org/10.1 093/ije/dyw319.

19. World Cancer Research Fund International/American Institute for Cancer Research. Continuous Update Project Report: Diet, Nutrition, Physical Activity and Bladder Cancer. Available at: https://wwwwcrforg/int/ continuous-update-project Accesed 10 Oct 2019.

20. La Vecchia C, Chatenoud L, Franceschi S, Soler M, Parazzini F, Negri E. Vegetables and fruit and human cancer: update of an Italian study. Int J Cancer. 1999;82(1):151-2. https://doi.org/10.1002/(sici)1097-0215(19990702 82:1<151:.:aid-ijc25>3.0.co;2-9.

21. Lin J, Kamat A, Gu J, Chen M, Dinney CP, Forman MR, et al. Dietary intake of vegetables and fruits and the modification effects of GSTM1 and NAT2 genotypes on bladder cancer risk. Cancer Epidemiol Biomark Prevent. 2009; 18(7):2090-7. https://doi.org/10.1158/1055-9965.Epi-08-1174.

22. Park SY, Ollberding NJ, Woolcott CG, Wilkens LR, Henderson BE, Kolonel LN. Fruit and vegetable intakes are associated with lower risk of bladder cancer among women in the Multiethnic Cohort Study. J Nutr. 2013;143(8):128392. https://doi.org/10.3945/jn.113.174920.

23. Negri E, La Vecchia C, Franceschi S, D'Avanzo B, Parazzini F. Vegetable and fruit consumption and cancer risk. Int J Cancer. 1991;48(3):350-4. https://doi. org/10.1002/ijc.2910480307.

24. Peluso M, Airoldi L, Magagnotti C, Fiorini L, Munnia A, Hautefeuille A, et al. White blood cell DNA adducts and fruit and vegetable consumption in bladder cancer. Carcinogenesis. 2000;21(2):183-7. https://doi.org/10.1093/ca rcin/21.2.183.

25. Chyou PH, Nomura AM, Stemmermann GN. A prospective study of diet, smoking, and lower urinary tract cancer. Ann Epidemiol. 1993;3(3):211-6. https://doi.org/10.1016/1047-2797(93)90021-u.

26. Vieira AR, Vingeliene S, Chan DS, Aune D, Abar L, Navarro Rosenblatt D, et al. Fruits, vegetables, and bladder cancer risk: a systematic review and meta-analysis. Cancer Med. 2015;4(1):136-46. https://doi.org/10.1002/ca m4.327.

27. Liu H, Wang XC, Hu GH, Guo ZF, Lai P, Xu L, et al. Fruit and vegetable consumption and risk of bladder cancer: an updated meta-analysis of observational studies. Eur J Cancer Prevent. 2015;24(6):508-16. https://doi. org/10.1097/cej.0000000000000119.

28. Yao B, Yan Y, Ye X, Fang $H, X u H$, Liu Y, et al. Intake of fruit and vegetables and risk of bladder cancer: a dose-response meta-analysis of observational studies. Cancer Causes Control. 2014;25(12):1645-58. https://doi.org/10.1 007/s10552-014-0469-0.

29. Xu C, Zeng XT, Liu TZ, Zhang C, Yang ZH, Li S, et al. Fruits and vegetables intake and risk of bladder cancer: a PRISMA-compliant systematic review and dose-response meta-analysis of prospective cohort studies. Medicine. 2015;94(17):e759. https://doi.org/10.1097/md.0000000000000759.

30. Wang F, Shan Y. Sulforaphane retards the growth of UM-UC-3 xenographs, induces apoptosis, and reduces survivin in athymic mice. Nutr Res. 2012; 32(5):374-80. https://doi.org/10.1016/j.nutres.2012.03.014.

31. Geng F, Tang L, Li Y, Yang L, Choi KS, Kazim AL, et al. Allyl isothiocyanate arrests cancer cells in mitosis, and mitotic arrest in turn leads to apoptosis via BCl-2 protein phosphorylation. J Biol Chem. 2011;286(37):32259-67. https://doi.org/10.1074/jbc.M111.278127. 
32. Abbaoui B, Riedl KM, Ralston RA, Thomas-Ahner JM, Schwartz SJ, Clinton SK, et al. Inhibition of bladder cancer by broccoli isothiocyanates sulforaphane and erucin: characterization, metabolism, and interconversion. Mol Nutr Food Res. 2012;56(11):1675-87. https://doi.org/10.1002/mnfr.201200276.

33. Hu H, Zhang XP, Wang YL, Chua CW, Luk SU, Wong YC, et al. Identification of a novel function of Id- 1 in mediating the anticancer responses of SAMC, a water-soluble garlic derivative, in human bladder cancer cells. Mol Med Rep. 2011;4(1):9-16. https://doi.org/10.3892/mmr.2010.380.

34. Wang YB, Qin J, Zheng XY, Bai Y, Yang K, Xie LP. Diallyl trisulfide induces $\mathrm{BCl}-2$ and caspase-3-dependent apoptosis via downregulation of Akt phosphorylation in human T24 bladder cancer cells. Phytomedicine. 2010; 17(5):363-8. https://doi.org/10.1016/j.phymed.2009.07.019.

35. Riboli E, Kaaks R. The EPIC Project: rationale and study design. European Prospective Investigation into Cancer and Nutrition. Int J Epidemiol. 1997; 26(Suppl 1):S6-14. https://doi.org/10.1093/ije/26.suppl_1.s6.

36. Tjonneland A, Olsen A, Boll K, Stripp C, Christensen J, Engholm G, et al. Study design, exposure variables, and socioeconomic determinants of participation in diet, cancer and health: a population-based prospective cohort study of 57,053 men and women in Denmark. Scand J Public Health. 2007;35(4):432-41. https://doi.org/10.1080/14034940601047986.

37. Clavel-Chapelon F, van Liere MJ, Giubout C, Niravong MY, Goulard H, Le Corre C, et al. E3N, a French cohort study on cancer risk factors. E3N Group. Etude Epidemiologique aupres de femmes de l'Education Nationale. Eur J Cancer Prevent. 1997;6(5):473-8. https://doi.org/10.1097/00008469-199710000-00007.

38. Boeing $H$, Korfmann A, Bergmann MM. Recruitment procedures of EPICGermany. European Investigation into Cancer and Nutrition. Ann Nutr Metab. 1999;43(4):205-15. https://doi.org/10.1159/000012787.

39. Panico S, Dello lacovo R, Celentano E, Galasso R, Muti P, Salvatore M, et al. Progetto ATENA, a study on the etiology of major chronic diseases in women: design, rationale and objectives. Eur J Epidemiol. 1992;8(4):601-8. https://doi.org/10.1007/bf00146383.

40. Riboli E, Hunt KJ, Slimani N, Ferrari P, Norat T, Fahey M, et al. European Prospective Investigation into Cancer and Nutrition (EPIC): study populations and data collection. Public Health Nutr. 2002;5(6b):1113-24. https://doi.org/10.1079/phn2002394.

41. Manjer J, Carlsson S, Elmstahl S, Gullberg B, Janzon L, Lindstrom M, et al. The Malmo Diet and Cancer Study: representativity, cancer incidence and mortality in participants and non-participants. Eur J Cancer Prevent. 2001; 10(6):489-99. https://doi.org/10.1097/00008469-200112000-00003.

42. Hallmans G, Agren A, Johansson G, Johansson A, Stegmayr B, Jansson JH, et al. Cardiovascular disease and diabetes in the Northern Sweden Health and Disease Study Cohort - evaluation of risk factors and their interactions. Scand J Public Health Suppl. 2003;61:18-24. https://doi.org/10.1080/14034 950310001432.

43. Beulens JW, Monninkhof EM, Verschuren WM, van der Schouw YT, Smit J, Ocke MC, et al. Cohort profile: the EPIC-NL study. Int J Epidemiol. 2010;39(5): 1170-8. https://doi.org/10.1093/ije/dyp217.

44. Davey GK, Spencer EA, Appleby PN, Allen NE, Knox KH, Key TJ. EPIC-Oxford: lifestyle characteristics and nutrient intakes in a cohort of 33883 meateaters and 31546 non meat-eaters in the UK. Public Health Nutr. 2003;6(3): 259-69. https://doi.org/10.1079/phn2002430.

45. Day N, Oakes S, Luben R, Khaw KT, Bingham S, Welch A, et al. EPIC-Norfolk: study design and characteristics of the cohort. European Prospective Investigation of Cancer. Br J Cancer. 1999;80(Suppl 1):95-103 PMID: 10466767.

46. Lund E, Dumeaux V, Braaten T, Hjartaker A, Engeset D, Skeie G, et al. Cohort profile: the Norwegian Women and Cancer Study--NOWAC--Kvinner og kreft. Int J Epidemiol. 2008;37(1):36-41. https://doi.org/10.1093/ije/dym137.

47. van den Brandt PA, Goldbohm RA, Van 't veer P, Volovics A, Hermus RJ, Sturmans F. A large-scale prospective cohort study on diet and cancer in the Netherlands. J Clin Epidemiol 1990;43(3):285-295. doi:https://doi.org/1 0.1016/0895-4356(90)90009-E.

48. White E, Patterson RE, Kristal AR, Thornquist M, King I, Shattuck AL, et al. VITamins And Lifestyle cohort study: study design and characteristics of supplement users. Am J Epidemiol. 2004;159(1):83-93. https://doi.org/10.1 093/aje/kwh010.

49. Giles GG, English DR. The Melbourne Collaborative Cohort Study. IARC Sci Publ. 2002;156:69-70 PMID: 12484128.

50. Milne RL, Fletcher AS, Maclnnis RJ, Hodge AM, Hopkins AH, Bassett JK, et al. Cohort Profile: The Melbourne Collaborative Cohort Study (Health 2020). Int J Epidemiol. 2017;46(6):1757-i. https://doi.org/10.1093/ije/dyx085.
51. Ozasa K, Shimizu Y, Sakata R, Sugiyama H, Grant EJ, Soda M, et al. Risk of cancer and non-cancer diseases in the atomic bomb survivors. Radiat Prot Dosim. 2011;146(1-3):272-5. https://doi.org/10.1093/rpd/ncr168.

52. Goossens ME, Isa F, Brinkman $M$, et al. International pooled study on diet and bladder cancer: the bladder cancer, epidemiology and nutritional determinants (BLEND) study: design and baseline characteristics. Arch Publ Health. 2016;74(1):30-9. https://doi.org/10.1186/s13690-016-0140-1.

53. Bassett JK, English DR, Fahey MT, Forbes AB, Gurrin LC, Simpson JA, et al. Validity and calibration of the FFQ used in the Melbourne Collaborative Cohort Study. Public Health Nutr. 2016;19(13):2357-68. https://doi.org/10.1 017/s1368980016000690.

54. Hodge A, Patterson AJ, Brown WJ, Ireland P, Giles G. The Anti Cancer Council of Victoria FFQ: relative validity of nutrient intakes compared with weighed food records in young to middle-aged women in a study of iron supplementation. Aust N Z J Public Health. 2000;24(6):576-83. https://doi. org/10.1111/j.1467-842x.2000.tb00520.x.

55. Kaaks R, Riboli E. Validation and calibration of dietary intake measurements in the EPIC project: methodological considerations. European Prospective Investigation into Cancer and Nutrition. Int J Epidemiol. 1997;26(Suppl 1): S15-25. https://doi.org/10.1093/ije/26.suppl_1.s15.

56. Zeegers MP, Goldbohm RA, van den Brandt PA. Are retinol, vitamin C, vitamin $\mathrm{E}$, folate and carotenoids intake associated with bladder cancer risk? Results from the Netherlands Cohort Study. Br J Cancer. 2001;85(7):977-83. https://doi.org/10.1054/bjoc.2001.1968.

57. Ferrari P, Slimani N, Ciampi A, Trichopoulou A, Naska A, Lauria C, et al. Evaluation of under- and overreporting of energy intake in the 24-hour diet recalls in the European Prospective Investigation into Cancer and Nutrition (EPIC). Public Health Nutr. 2002;5(6b):1329-45. https://doi.org/10.1079/phn2 002409

58. Poortvliet E, Klensin J, Kohlmeier L. Rationale document for the Eurocode 2 food coding system (version 91/2). Eur J Clin Nutr. 1992;46(Suppl 5):S9-S24 Rationale document for the Eurocode 2 food coding system.

59. Giganti MJ, Luz PM, Caro-Vega Y, Cesar C, Padgett D, Koenig S, et al. A comparison of seven cox regression-based models to account for heterogeneity across multiple HIV treatment cohorts in Latin America and the Caribbean. AIDS Res Hum Retrovir. 2015;31(5):496-503. https://doi.org/1 0.1089/aid.2014.0241.

60. Al-Zalabani AH, Stewart KF, Wesselius A, Schols AM, Zeegers MP. Modifiable risk factors for the prevention of bladder cancer: a systematic review of meta-analyses. Eur J Epidemiol. 2016;31(9):811-51. https://doi.org/10.1007/s1 0654-016-0138-6.

61. Willett WC, Howe GR, Kushi LH. Adjustment for total energy intake in epidemiologic studies. Am J Clin Nutr. 1997;65(4 Suppl):1220S-8S; discussion 9S-31S. https://doi.org/10.1093/ajcn/65.4.1220S.

62. Bagnardi V, Zambon A, Quatto P, Corrao G. Flexible meta-regression functions for modeling aggregate dose-response data, with an application to alcohol and mortality. Am J Epidemiol. 2004;159(11):1077-86.

63. Buchner FL, Bueno-de-Mesquita HB, Ros MM, Kampman E, Egevad L, Overvad $\mathrm{K}$, et al. Consumption of vegetables and fruit and the risk of bladder cancer in the European Prospective Investigation into Cancer and Nutrition. Int J Cancer. 2009;125(11):2643-51. https://doi.org/10.1002/ijc.24582.

64. Ros MM, Bueno-de-Mesquita HB, Kampman E, Buchner FL, Aben KK, Egevad $L$, et al. Fruit and vegetable consumption and risk of aggressive and nonaggressive urothelial cell carcinomas in the European Prospective Investigation into Cancer and Nutrition. Eur J Cancer. 2012;48(17):3267-77. https://doi.org/10.1016/j.ejca.2012.05.026.

65. Ntzeros K, Stamatakos M, Stokidis S, Louka G. Bladder cancer: the hormonal dependence enigma and a new hormonal player. Indian J Surg. 2015; 77(Suppl 3):1502-3. https://doi.org/10.1007/s12262-014-1133-3.

66. Matsuo K, Hiraki A, Ito H, Kosaka T, Suzuki T, Hirose K, et al. Soy consumption reduces the risk of non-small-cell lung cancers with epidermal growth factor receptor mutations among Japanese. Cancer Sci. 2008;99(6): 1202-8. https://doi.org/10.1111/j.1349-7006.2008.00812.x.

67. Bauer RM, Huebner W. Gender differences in bladder control: from babies to elderly. World J Urol. 2013;31(5):1081-5. https://doi.org/10.1007/s00345013-1132-1.

68. Emanuel AS, McCully SN, Gallagher KM, Updegraff JA. Theory of planned behavior explains gender difference in fruit and vegetable consumption. Appetite. 2012;59(3):693-7. https://doi.org/10.1016/j.appet.2012.08.007.

69. Leblanc V, Bégin C, Hudon AM, Royer MM, Corneau L, Dodin S, et al. Gender differences in the long-term effects of a nutritional intervention 
program promoting the Mediterranean diet: changes in dietary intakes, eating behaviors, anthropometric and metabolic variables. Nutr J. 2014;13: 107. https://doi.org/10.1186/1475-2891-13-107.

70. Stea TH, Nordheim O, Bere E, Stornes P, Eikemo TA. Fruit and vegetable consumption in Europe according to gender, educational attainment and regional affiliation-a cross-sectional study in 21 European countries. PLoS One. 2020;15(5):e0232521. https://doi.org/10.1371/journal.pone.0232521.

71. WCRF/AICR. Discover how diet, nutrition and physical activity affect cancer risk. Available at: https://www.wcrf.org/dietandcancer/interactive-cancer-riskmatrix\#download_block. Accessed 10 Oct 2019.

72. Continuous Update Project. Available at: https:/wwwwwcrforg/int/ continuous-update-project. Accessed Dec 25th, 2019.

73. Cust AE, Skilton MR, van Bakel MM, Halkjaer J, Olsen A, Agnoli C, et al. Total dietary carbohydrate, sugar, starch and fibre intakes in the European Prospective Investigation into Cancer and Nutrition. Eur J Clin Nutr. 2009; 63(Suppl 4):S37-60. https://doi.org/10.1038/ejcn.2009.74.

74. Tanaka T, Shnimizu M, Moriwaki H. Cancer chemoprevention by carotenoids. Molecules. 2012;17(3):3202-42. https://doi.org/10.3390/ molecules 17033202.

75. Padayatty SJ, Katz A, Wang Y, Eck P, Kwon O, Lee JH, et al. Vitamin C as an antioxidant: evaluation of its role in disease prevention. J Am Coll Nutr. 2003;22(1):18-35. https://doi.org/10.1080/07315724.2003.10719272.

76. Kang ZC, Tsai SJ, Lee H. Quercetin inhibits benzo [a]pyrene-induced DNA adducts in human Hep G2 cells by altering cytochrome P-450 1A1 gene expression. Nutr Cancer. 1999;35(2):175-9. https://doi.org/10.1207/s15327914 nc352_12.

77. Liu RH. Dietary bioactive compounds and their health implications. J Food Sci. 2013;78(Suppl 1):A18-25. https://doi.org/10.1111/1750-3841.12101.

78. Michaud DS, Spiegelman D, Clinton SK, Rimm EB, Willett WC, Giovannucci EL. Fruit and vegetable intake and incidence of bladder cancer in a male prospective cohort. J Natl Cancer Inst. 1999;91(7):605-13. https://doi.org/10.1 093/jnci/91.7.605.

79. Larsson SC, Andersson SO, Johansson JE, Wolk A. Fruit and vegetable consumption and risk of bladder cancer: a prospective cohort study. Cancer Epidemiol Biomark Prevent. 2008;17(9):2519-22. https://doi.org/10.1158/1 055-9965.Epi-08-0407.

80. Abbaoui B, Riedl KM, Ralston RA, Thomas-Ahner JM, Schwartz SJ, Clinton SK, et al. Inhibition of bladder cancer by broccoli isothiocyanates sulforaphane and erucin: characterization, metabolism, and interconversion. Mol Nutr Food Res. 2012:56(11):1675-87.

81. Liu B, Mao Q, Lin Y, Zhou F, Xie L. The association of cruciferous vegetables intake and risk of bladder cancer: a meta-analysis. World J Urol. 2013;31(1): 127-33. https://doi.org/10.1007/s00345-012-0850-0.

82. Olsen H, Grimmer S, Aaby K, Saha S, Borge Gl. Antiproliferative effects of fresh and thermal processed green and red cultivars of curly kale (Brassica oleracea L. convar. acephala var. sabellica). J Agric Food Chem. 2012;60(30): 7375-83. https://doi.org/10.1021/jf300875f.

83. Tang L, Zirpoli GR, Jayaprakash V, Reid ME, McCann SE, Nwogu CE, et al. Cruciferous vegetable intake is inversely associated with lung cancer risk among smokers: a case-control study. BMC Cancer. 2010;10:162. https://doi. org/10.1186/1471-2407-10-162.

84. Hecht SS. Chemoprevention of cancer by isothiocyanates, modifiers of carcinogen metabolism. J Nutr. 1999;129(3):768s-74s. https://doi.org/10.1 093/jn/129.3.768S.

85. Hecht SS. Inhibition of carcinogenesis by isothiocyanates. Drug Metab Rev 2000;32(3-4):395-411. https://doi.org/10.1081/dmr-100102342.

86. Hecht SS, Carmella SG, Murphy SE. Effects of watercress consumption on urinary metabolites of nicotine in smokers. Cancer Epidemiol Biomark Prevent. 1999:8(10):907-13.

87. Loftfield E, Freedman ND, Inoue-Choi M, Graubard BI, Sinha R. A prospective investigation of coffee drinking and bladder cancer incidence in the United States. Epidemiol. 2017;28(5):685-93. doi:https://doi.org/10.1097/ede. 0000000000000676.

\section{Publisher's Note}

Springer Nature remains neutral with regard to jurisdictional claims in published maps and institutional affiliations.

\section{Ready to submit your research? Choose BMC and benefit from:}

- fast, convenient online submission

- thorough peer review by experienced researchers in your field

- rapid publication on acceptance

- support for research data, including large and complex data types

- gold Open Access which fosters wider collaboration and increased citations

- maximum visibility for your research: over $100 \mathrm{M}$ website views per year

At BMC, research is always in progress.

Learn more biomedcentral.com/submissions 